\title{
Effects of education on attitudes to deliberate self-harm
}

\author{
Gill Turnbull and Trudie Chalder
}

\begin{abstract}
Accident and emergency (A\&E) staff completed a general knowledge and aftitude questionnaire related to suicide and deliberate self-harm (DSH) before and after a teaching package. The results showed an increase in general knowledge while aftludes remained the same. Following the teaching package there was an increase in the number of patients who contacted the Specialist Service for DSH.
\end{abstract}

There has been increased interest in suicide since the publication of the Government's White Paper, Health of The Nation (1992), and the Government's target to reduce suicides by $15 \%$ by the year 2000 .

The current focus on suicide offers an opportunity for attitudes and behaviour towards individuals who self-harm to be examined, understood and changed. To date, results of research into the effects of knowledge and experience of suicide and DSH are conflicting. Final year medical students who received a teaching session about patients who self-harm (Barber et al, 1975) and a group of final year medical students who had completed their psychiatric attachment (Goldney \& Bottrill, 1985) both recorded more unfavourable attitudes following their experience. It has been suggested that in general, attitudes to attempted suicide harden as the student approaches graduation. However, other studies show a positive relationship between knowledge and positive attitudes following specific teaching on suicide (Swain \& Domino, 1985; Morgan et al, 1996).

At least 100000 people in the UK deliberately harm themselves each year (Wells, 1981). Many will go on to harm themselves again and $1 \%$ will kill themselves in the year following the first attempt (Hawton \& Fagg, 1988). The consequent effects on the individual, the family and society are immense. It is therefore vital that these patients are assessed and offered appropriate treatment and follow-up to minimise the likelihood of further self-harm.

The aim of this study was to investigate the effects of a training session on staffs general knowledge of and attitudes to suicide and selfharm. It was envisaged that a greater awareness of the subject could positively alter attitudes and lead to improved patient care. Outcome of patient care was measured by the number of patients who requested specialist follow-up after discharge from the accident and emergency (A\&E) department.

\section{The study}

All staff were recruited from the A\&E department and emergency ward of King's College Hospital. Each received a one-hour group teaching session over a four-week period from the liaison nurse (GT). In addition, the doctors were taught how to complete a mental state examination by a liaison psychiatrist.

\section{Instruments}

A general knowledge questionnaire included questions relating to the epidemiology and main risk factors for suicide and self-harm. The Inventory of Negative Attitudes (Morgan et al, 1996) investigated different beliefs about suicide. Five responses are possible, ranging from strongly agree to strongly disagree.

Subjects completed the two measures prior to the teaching session. Repeat questionnaires with self-addressed envelopes were sent to each subject on average six weeks after the first teaching session.

\section{Teaching}

The aims of the teaching session were: to impart knowledge on the nature of suicide and DSH with the aim of improving care given to the patient; to give information on the specialist follow-up service.

\section{Findings}

Fifty-five trained nurses were invited to attend the sessions and $37(67 \%)$ took part. Length of experience varied between 2.5 years and 24 years with a mean of 8.8 years. Fourteen $(87 \%)$ doctors out of 16 attended. The doctors' experience ranged from house officer to consultant. 
The total number of completed questionnaires for both groups before the teaching session was $70 \%(50 / 71)$. This dropped to $53 \%(26 / 50)$ after the teaching session.

\section{Previous training}

Two nurses had completed their Registered Mental Nurse training and one had worked in a self-harm team at another hospital. Otherwise none of the subjects had received more than 1-2 hours of formal training.

\section{Questionnaires}

There was a significant increase in the total number of correct answers to the general knowledge questionnaire after the teaching session. Correct responses increased from $29 \%$ to $63 \%$, $(t=-2.32$, d.f. $=20, P<0.03)$.

On the attitude questionnaire, $83 \%$ of the sample expressed equivocal or positive attitudes towards DSH and suicide before the teaching session, leaving little room for improvement. This proportion increased to $88 \%$ after the intervention but did not reach statistical significance $(t=-1.64$, d.f. $=23, P=0.114$, NS).

\section{Number of patient contacts}

Eight patients contacted the team for an assessment five months prior to the teaching, while 18 contacted the team during the five-month followup period $\left(\chi^{2}=5.19, P<0.02\right)$.

\section{Comments}

This study showed that after implementation of a teaching package about suicide and DSH, the general knowledge of staff improved while attitudes did not become more favourable. In addition, the number of patients who contacted the Specialist Service increased up to five-months follow-up but this was not sustained long-term.

There are some limitations to this study. Although the attitude questionnaire had been tested for validity, more rigorous testing of both questionnaires is needed to ascertain their reliability and validity. The number of subjects in this study was small so the results should be treated with caution.

Overall, the results suggest that medical and nursing staff have a positive attitude to the prevention of suicide and feel they can have an impact on suicide rates. Indeed, their attitudes and knowledge of DSH and suicide prior to the intervention suggests an already acquired awareness. Morgan et al (1996) found that a formal lecture on suicide prevention increased the proportion of expressed positive attitudes immediately following the lecture. In this study, people's attitudes were examined one month after the teaching had taken place. This suggests that in order to sustain attitudinal change, regular teaching should be provided.

A survey was carried out on the amount of formal teaching on suicide and self-harm the staff had received before and after qualifying. Despite the fact that the subject of DSH is clearly one which involves many conflicts and dilemmas for all professionals, the average amount of teaching received during either medical or nurse training was minimal. This suggests that this is a very neglected area. Educators need to be aware of this deficiency and cover the subject more comprehensively in professional training.

\section{Acknowledgements}

We are grateful to Cathy Cox for conducting one of the teaching sessions and Dr Jan Neeleman for commenting on an earlier draft of this paper.

\section{References}

Barber, J. H., Hodgkin, G. K., PATEl, A. R., et al (1975) Effects of teaching on medical students attitudes to self-poisoning. British Medical Journal, 2, 431.

DEPARTMENT OF HEALTH (1992) Health of the Nation: Strategy for Health in England. London: HMSO.

GOLDNEY, D. \& BOTTRIL, A. (1980) Attitudes to patients who attempt suicide. The Medical Journal of Australia. December 27, 717-720.

HAWTON K. \& FAGG. J. (1988) Suicide and other causes of death, following attempted suicide. British Joumal of Psychiatry, 162, 359-366.

MoRgan, H. G., Evans, M., Johnson, C., et al (1996) Can a lecture influence attitudes to suicide prevention? Journal of the Royal Society of Medicine, 89, 87-90.

SwaIN, B. \& Domino. G. (1985) Attitudes toward suicide among mental health professionals. Death Studies, 8. $455-468$.

WELL, N. (1981) Suictde and Deliberate Self-Harm. London: HMSO.

*Gill Turnbull, Psychiatric Liaison Nurse, Department of Psychological Medicine. The Bethlem Royal and Maudsley Hospital Trust. Denmark Hill, London SE5 8AZ; Trudie Chalder, Lecturer, Department of Psychological Medicine, Institute of Psychiatry, 103 Denmark Hill, London SE5 8AZ

*Correspondence 